\title{
SOMUT OLMAYAN KÜLTÜREL MİRAS UNSURLARINDAN YÖRESEL YIYECEKLER: KINALI EKMEK
}

\section{LOCAL FOOD FROM INTANGIBLE CULTURAL HERITAGE ELEMENTS: "HENNEAD BREAD"}

Begüm KURT*

\begin{abstract}
ÖZ: Milletler kendilerine özgü yaşam tarzları, geçmişten günümüze taşıdıkları pratikler ve maddi-manevi değerleri ile farklılık kazanarak evrensel ölçekte tözünü oluşturan unsurlarla kendilerine yer edinirler. Kültürel unsurlar zaman içerisinde ilerleme ve gelişme kaydetmekle birlikte varlıklarına duyulan ihtiyaç ve yaşatılmalarına verilen önemle istikrar içinde tekrarlanmakta, temel niteliklerini koruyarak özünü yeni kılıflara bürünerek sürdürmekte ve böylece toplumların diğerlerinden ayrımlı bir yapı olușturmasını sağlamaktadır. Küreselleșmenin etkilerinin her geçen gün arttığı günümüzde ulusal kültürün her bir değeri daha da önem kazanmakta, halk kültürünün taşınması ve aktarımı bağlamında birtakım refleksler belirmektedir. Bu bağlamda sahip olduğu zenginlikleriyle aktarımı gerekli, somut olmayan kültürel unsurların kaynakları arasında halk mutfağı bulunmaktadır. Dünyanın sayılı mutfakları arasında yer alan Türk mutfağı milli kültürün zengin bir bölümünü sergilemektedir. Temeli göçer kültüre dayanan, kronolojik yaşam çizgisinde coğrafya, yaşam koşulları ve kültürel değişimlerle varlık kaynaklarını genişleten Türk mutfak kültürü birçok bileşenden oluşmaktadır. Ulusal mirasın bir parçası olarak bölgelere göre farklılıklar içermektedir. Geleneksel yiyeceklerin yöreye özgü çeşitlerinin değerlendirilmesi bu bağlamda bütüne ait farklılıkların varlığına dikkati çekerek Türk halk mutfağı çalıșmaları adına yarar sağlayacaktır. Bu amaçla çalışmada somut olmayan kültürel mirasın doğa ve evrenle ilgili bilgi ve uygulamaları kapsamında değerlendirilen geleneksel yiyecekler Malatya ili Doğanşehir ilçesine bağlı Polat kasabası halk mutfağının yöreye özgü yiyeceği kınalı ekmek üzerinden incelenmiş, yazılı ve sözlü kaynaklardan elde edilen verilerle ekmeğin folklorik değeri üzerinde durulmuștur. Böylece kültürel bir varlık alanı olan Türk mutfağının zenginliğini yansıtmak ve farklı alanlardaki dirayetini örnekler aracılığıyla ortaya koymak amaçlanmıştır.
\end{abstract}

Anahtar Kelimeler: Somut olmayan kültürel miras, Türk halk mutfă̆ı, yöresel yiyecek, kınalı ekmek, Polat kasabası.

ABSTRACT: Nations acquire a place for themselves with their unique lifestyles, practices they carry from past to present, and material and spiritual values, making a difference on a universal scale. While cultural elements make progress and progress over time, they are repeated in stability with the importance given to the need and survival of their existence, maintaining their basic qualities and maintaining their essence in New sheaths, thus enabling societies to form a distinctive structure. Today, every value of national culture becomes more important and responsibilities appear in the context of the transport and transfer of folk culture. In this context, among the sources of intangible cultural elements that need to be transferred with their wealth are folk cuisine. Turkish cuisine, which is among the most important cuisines of the world, exhibits a rich part of the national culture. Turkish culinary culture, based on migratory culture

\footnotetext{
* Dr. Öğretim Üyesi - Çağ Üniversitesi Fen Edebiyat Fakültesi Türk Dili ve Edebiyatı Bölümü/Mersin - begumkurt@windowslive.com (ORCID ID: 0000-0002-4509-5125) 
and expanding its sources of existence through geography, living conditions and cultural changes in chronological life lines, consists of many components. It includes differences by region as part of national heritage. The evaluation of the local varieties of traditional foods will benefit Turkish folk cuisine by drawing attention to the existence of all differences in this context. For this purpose, traditional foods evaluated within the scope of intangible cultural heritage knowledge and applications related to nature and the universe were examined on the sample of kınalı bread, the local food of Polat town of Doğanşehir District of Malatya province, and the folkloric value of local foods was emphasized with the data obtained from written and oral sources. Thus, it is aimed to reflect the richness of Turkish cuisine, which is a cultural asset area, and to demonstrate its strength in different areas through examples.

Keywords: Intangible cultural heritage, Turkish folk cuisine, local food, hennead bread, Polat town.

\section{Giriş}

İnsanoğlu temel gereksinimlerini kültürüne özgü davranış ve biçimlerde gerçekleştirerek ihtiyaç olgusuna kendilik değer yükler. Dolayısıyla temel gereksinimlerden biri olan beslenmeyi sadece hayatı devam ettirme olayı olarak düşünmek doğru olmaz, temel bir ihtiyacı karşılamanın ötesinde yeme-içme eylemi toplumsal özelliklerin bir alametidir. Üretim-tüketim ilişkileri ve bunun çevresinde oluşan yaşam faaliyetleri, yiyeceklerin sahip olduğu sembolik anlamlar, töresel ve törensel özellikleri ile kültürel analiz çalışmalarında bir kaynaktır. Nitekim özel gün yemekleri anlam yüklenen birer araç olarak kültürel işlem alanında yer edinmiştir. Beslenme kültürü öz varlığı dışa aksettiren bir olgudur. Her toplumun kendine özgü bir mutfak kültürü olduğu gibi Türklerin de toplumsal benliğini yansıtan bir mutfak kültürleri vardır. Temeli göçer kültüre dayanan, kronolojik yaşam çizgisinde coğrafya, yaşam koşulları ve kültürel değişimlerle varlık kaynaklarını genişleten Türk mutfak kültürü birçok bileşenin temsil bulmuş biçimidir. Ulusal mirasın bir parçası olarak bölgelere göre farklılıklar içermektedir. Geleneksel yiyeceklerin yöreye özgü çeşitlerinin değerlendirilmesi bu bağlamda bütüne ait farklılıklara ve muhteliflere dikkati çekerek Türk halk mutfağı çalışmaları adına yarar sağlayacaktır. Bu gaye ile çalışmada somut olmayan kültürel mirasın doğa ve evrenle ilgili bilgi ve uygulamaları kapsamında değerlendirilen geleneksel yiyecekler, Malatya ili Doğanşehir ilçesine bağlı Polat kasabası halk mutfağının özel yiyeceği kınalı ekmek örneği üzerinden incelenmiştir. Yazılı ve sözlü kaynaklardan elde edilen verilerle oluşturulan çalışmada Türk mutfağının temel besin maddesi olan ekmeğin Türk kültüründe ve araştırma alanı olan Polat yöresindeki önemi ile somut olmayan kültürel miras unsuru olarak kınalı ekmeğin folklorik değeri konu edilmiştir.

Bugün mahalle statüsünde bulunan Polat kasabası, kayısının ana vatanı olarak nitelendirilen Malatya ilinin güneybatısında yer alan Doğanşehir ilçesinin kuzeybatı yönünde konumlanmıştır. Dört tarafı dağlarla çevrili Polat ovasının eteklerine kurulu olan kasaba, yörenin en önemli kültürel merkezlerinden biridir. Kasabanın kuruluş tarihi kesin 
olarak bilinmemekle birlikte bölgede yer alan kalıntılar tarihinin eski dönemlere uzandığının bir göstergesidir. Töresine bağlı kasaba halkı kültürel değerlerini, âdet ve geleneklerini günümüze de taşımayı başarmıștır. Canlı bir halk kültürü olan kasabanın sahip olduğu zenginlikler içerisinde köklü ve renkli yapısını gösteren mutfak kültürü bedihtir. Yöre halkı üretken ve yaratıcı yapısıyla mutfak hazinesi içerisinde birçok özgün tada yer sağlamıştır. Bu türden yerel mutfak kültürü ürünleri, çevresinde oluşan varlıklarını ve yapım nedenlerini izaha bağlı hikâyeler, fıkra, atasözü gibi sözlü verimler, iletişim göstergesi olarak kullanım ölçütleri ve belirli zamanlarda yapılan özel çeşitleri ile simge yüklü değerlere sahip folklorik bir önem arz etmektedir.

\section{Somut Olmayan Kültürel Miras: Geleneksel Yiyecekler}

Somut olmayan kültürel miras terimi bir kültürel miras koruma programının adı olarak ortaya çıkmış ve yayılmıştır (Oğuz, 2013: 5). Somut olmayan kültürel miras, insanlığın varoluşundan bu yana tabiata kattığı, hayatında kullandığı, nesilden nesile günümüze kadar aktardığı her şeyi korunma ihtiyacından ortaya çıkan ortak bir bilinçtir. Amacı bu ortak kültürel bilincin değerlerini belirleyip kayıt altına almak ve böylece kuşaklar arası aktarımını sağlamak olan uluslararası bir kurum olarak UNESCO önemli bir görev üstlenmektedir. Ülkeler UNESCO ile somut olmayan kültürel miras sözleşmesi yaparak bu değerlerini, uluslararası literatürde kayıt altına alabilme imkânına sahip olabilmektedir (Başkan ve Avcıkurt, 2015: 618). Somut Olmayan Kültürel Mirasın (SOKÜM) Korunması Sözleşmesi, toplumların kültürel kimliklerinin bir bölümü olarak gördüğü ve nesilden nesile ileterek günümüze kadar getirdiği somut olmayan kültürel miraslarının korunmasına ve sonraki nesillere iletilmesini sağlayacak faaliyetleri ortaya koymaktadır (Oğuz, 2009: 8).

İnsanların yaşayış biçimini, geleneklerini, göreneklerini içermesinden dolayı insanlık tarihi kadar eski olan kültürel mirası, somut ve somut olmayan kültürel miras olarak iki grupta incelenmektedir (Saruhan, 2012: 26). Somut olmayan kültürel miras değerlerini, geçmişten miras kalan gelenekler, müzik, dans, dil, din, mutfak kültürü ve yemek pişirme tarzları ve festivaller oluştururken; anıtlar, tarihi binalar, çiftlikler, yemekler, müzik aletleri, evler, müzeler, kültürel dokuya sahip eşyalar, el sanatları ürünleri ve arkeolojik kalıntılar da somut kültürel mirası oluşturmaktadır (Çapar ve Yenipınar, 2016: 103). Somut olmayan kültürel miras; her düzeydeki bireylerin ve insan topluluklarının değerler ve ahlak standartları aracılığı ile dünyayı kavrayış șekillerini ifade etmelerine olanak veren bir dizi yaşayan ve sürekli olarak yeniden yaratılan yol ve yöntemlerden, bilgiden ve ifade yollarından oluşur. Somut olmayan kültürel miras insan toplulukları arasında bir ait olma ve devamlılık yaratır; bu nedenle de yaratıcılığın ve kültürel yaratının ana ögelerinden biri olarak kabul edilir (Artun, 2012: 455). 
Toplumlar taşıdıkları farklılıklarla kendilerine has bir bütün olma özelliğine kavuşmakta, bir tine sahip olmaktadır. Bir başka deyişle kendilerine özgü yaşam tarzları, kuşaklardır sürdürdükleri pratikler ve maddi-manevi değerleri ile diğer toplumlardan ayrılarak evrensel ölçekte tözünü oluşturan bu unsurlarla varlık göstermektedirler. Bu bağlamda küreselleşmenin etkilerinin her geçen gün arttığı günümüzde ulusal kültürün her bir değeri daha fazla önem kazanmakta, bu da somut olmayan kültürel unsurların muhafaza ve aktarımını gerekli kılmaktadır. Söz konusu değerler arasında zengin kaynakları ile halk mutfağı da bulunmaktadır.

Mahmut Tezcan'a göre kültür ne yiyeceğimizin temel belirtisidir ve öğrenilmiştir. Yiyecek alışkanlıkları da küçük yaşta öğrenilir ve öğrenildikten sonra uzun süre değişmez, bu şekilde yiyecekler kültürün bütünleyici parçalarıdır (Tezcan, 2000: 1). Temininden tüketimine kadar yemekle ilgili oluşumlar insanların topluluksal davranışını, dolayısıyla kültürü önemli bir konu haline getirmiștir. İnsan birliktelikleri kurumsallaşmış davranış örüntüleriyle şekillenen oluşumlardır (Beşirli, 2010: 168). Türk kültür hayatının önemli bir unsuru olan Türk mutfağı; aynı zamanda dünyanın en ünlü birkaç mutfağından biridir. Çeşit ve lezzet açısından olduğu kadar, yiyecek hazırlama ve pişirme teknikleri, özel gün yemekleri, mutfak araç ve gereçleri açısından da zengindir (Sürücüoğlu ve Özçelik, 2008: 1289). Yemek malzemeleri, etnik veya sınıf grubunun sinırları gibi birey statüsünü gösterebilir. Bununla birlikte yemek pişirmenin diğer birçok karışık aşamaları da (kapkacak, pişirme ve yapılanlar) sosyal ve kültürel mesajların aktarılmasını sağlar (Goode, 2005: 172).

Beslenme kültürü; sosyal yaşam, coğrafya, din ve iklim gibi faktörler nedeniyle toplumdan topluma değişim gösterebilir. Beslenme ihtiyacının giderilmesi, bireyin toplumla olan etkileşimini artırmakta ve onu toplumun bir parçası haline getirmektedir (Göde ve Tatlıcan, 2016: 126). Yemek yalnızca insanları bir yere ve kültürleri bir toprak parçasına bağlamaz aynı zamanda bize kim olduğumuz ve nereye ait olduğumuz hakkında da bilgi verir (Delind, 2006: 136; akt. Çapar ve Yenipınar, 2016: 101). Bir bakıma yemek, yenilen șeyin sahip olduğu özelliği de benimsemek ve onunla bütünleşmektir. Başka bir deyişle yemeği yiyen kişi, onun ait olduğu kültürün de bir parçası olur. Kültürün ürünü olan yemek, o yemeği yiyen kişiyi kültürel düzenin ve toplumsal evrenin bir parçası yapar. Yeme alışkanlıkları ortak kimliğin dayanağı ve dolayısıyla başkalık kazanmanın dayanağı olarak görülmektedir (Bessiere, 1998: 24; akt. Çapar ve Yenipınar, 2016: 101).

Dolayısıyla beslenme kültürü insan kümelerinin ayrı birer bütün olmasını sağlayan etkenlerden biri olarak, toplumu oluşturan insanların yaşamsal ihtiyaçlarını yer aldıkları bütüne özgü bir biçimde karşılamasına neden olmakta ve bu da halk mutfağı kavramının ortaya çıkmasına ve değer yüklenmesine yol açmaktadır. Bir milletin ruhunu ve geçmiş yaşam izlerini nakşettiği mutfak kültürünü değerlendirebilmek için o mutfağı şekillendiren 
başat unsurları göz önünde bulundurmak gerekir. "Türk mutfağı denince hatıra, Türk tarihi gelmelidir. Çünkü bir millet, kolaylıkla ağzının tadını kaybedemez. Binlerce yıldan beri alıştığı yemeğinden vazgeçemez. Ayrıca mutfaktaki kadın da tutucudur. Yemek pişirme geleneği atalarından gelir. Şimdiki gibi, görgü ve bilgiyi değiștirebilecek, bir çevresi de yoktur. Ancak her milletin mutfağının temelini oluşturan en önemli neden, ekonomik nedendir." (Ögel, 1982: 15).

Ekonomik nedenlerin temelinde de yine coğrafyaya bağllık yatmaktadır. "Geleneksel mutfakların teşekkülünde milli kültür ile birlikte coğrafya çok önemli bir etkiye sahiptir. Dünyanın çeşitli bölgelerine yerleşmiş Türk boylarının mutfağında gördüğümüz özelliklerin biri de kaynağında tarım ve hayvancılığa dayalı bu mutfağın yerleşme yerinin coğrafi konumundan etkilendiğidir. Yerleşme yerinin fiziki, beşeri en çok da ekonomik durumu yemeklerimizin ortaya çıkıșını, yayılışını ve yaygınlığını belirlediğine göre Türk yemeklerinin çeşitli bölgelerimiz ve yerleşme yerlerimiz arasında değişiklikler göstermesi doğaldır." (Birer, 1990: 253).

Türk mutfağının kökleri kadim coğrafya Orta Asya'ya kadar uzanmaktadır. Orta Asya göçebe insanının et ve mayalanmış süt ürünlerini kullanmaları, Mezopotamya'da yetişen tahıllar, Akdeniz çevresinin sebze ve meyveleri, Güney Asya'nın baharatı ile birleşerek zengin bir yemek kültürünü ortaya çıkarmıștır. Orta Asya'da yaşayan Türklerin ilk besinleri buğday unu, süt ve süt ürünleri, at ve koyun eti iken, içtikleri de kısrak sütünden hazırladıkları kımızdan ibaret olmuștur. Türklerin yaşadıkları bu bölgede meyve ve sebze çeşitleri sınırlı olduğu halde yaptıkları yemeklerin basit olmadığı görülmektedir (Kabak, 2017: 284).

Türkler Orta Asya'dan göç ederken gittikleri yerlere geleneklerini de götürmüşlerdir. Anadolu'ya yerleșen Türkler, eski beslenme alışkanlıklarını muhafaza etmekle birlikte, yeni yemek kültürleriyle de karşılaşmış ve bunlardan etkilenmişlerdir. Selçuklu ve Osmanlı devletlerinin imparatorluk özelliklerinden dolayı pek çok farklı etnik ve dini grubu bünyesinde bulundurmuş olmaları Türk mutfağının zenginliğini sağlayan önemli unsurlardır (Demirgül, 2018: 105).

\section{Polat Yöresi Mutfak Kültüründen Kınalı Ekmek}

Coğrafi konum ve iklim koşullarının etkili olduğu bir halk mutfağına sahip olan yörelerden biri Malatya'dır. Yaşam koşullarının geçim kaynaklarını etkilediği ve mutfak kültürünü biçimlendirdiği Malatya yöresi varsıl yapısı içerisinde halk mutfağı, yoğunlukta kullanılan malzemelerin kendine özgülüğünü belirlediği bir özelliğe sahiptir. Örneğin bulgurun her çeşidinin kullanıldığı üç yüzün üzerinde yemek çeşidi yöre halk mutfağının ana malzemesinin bulgur olduğunu göstermektedir. Yöre yerli üretim tahıl ürünlerinin yaygın kullanım bulduğu un, et ve süt ürünleri gibi ana besin maddeleri ile elde edilen yiyeceklerdeki çeşitlilik göze çarpmaktadır. 
Bilindiği gibi Türk mutfağının temel ürünleri arasında ekmek ve çeşitleri bulunmaktadır. Muhtelif tahıl unlarının, su, tuz ve maya gibi malzemelerle karıştırılmasıyla elde edilen hamurun değişik şekillerde, türlü ilave malzemelerle ve farklı pişirme teknikleri ile çok eski zamanlardan itibaren Türk mutfağında üretim ve tüketim bulduğu bilinmektedir. "İnsanların beslenmesi ve yemek kültürü içerisinde ekmeğin önemli bir yeri bulunmaktadır. Ülkelerin gelişmişlik düzeyine ve bireylerin sosyoekonomik yapısına bağlı olarak tüketilen ekmek miktarı değişiklik gösterse de günlük alınan enerjinin önemli bir bölümü ekmekten sağlanmaktadır." (Baysal ve Över 1994: 42). Şu demek ki; "ekmek, insanoğlunun uygarlık serüveni içinde binlerce yıldır, vazgeçemediği bir temel besin kaynağı olarak yer almaktadır. Ekmek, bu süreç içerisinde değiş̧ik toplumlarda meydana getirdiği kültürle günlük hayatımızda var olmaya devam etmektedir. Temel besin kaynağı olma özelliği dışında folklorumuzdan, edebiyatımıza; batıl inanışlarımızdan kutsal kitaplardaki metinlere; şarkılardan türkülere kadar insanoğlunun oluşturduğu tüm kültürlerin nerede ise her noktasında ekmek vardır." (Bayoğlu, 2014: 164).

Pek çok kültür ürünü içerisinde yer bulan ekmek, Malatya ili halk kültüründe de anonim halk edebiyatı ürünleri içerisinde sahip olduğu değer ve önemle atasözleri ve deyimler başta olmak üzere sözel verimlerde, pek çok âdet ve inançta kullanım bulmuştur. Bir işin ehline yaptırılmasının önemini vurgulayan "Ekmeğini ekmekçiye ver, bir ekmek de üstüne sen ver." (Kurt, 2012: 488) atasözünde; genellikle önüne çıkan fırsatları değerlendiremeyen, kendi yararını bilmeyen veya nankörlük eden kişiler için kullanılan "Ekmeğini yağıyla tepmek" (Kurt, 2012: 499) deyiminde; "Ekmek at, sen it olasın koşa koşa yetişemeyesin." (Kurt, 2012: 522) veya "Yek ekmeğe muhtaç olasın." (Kurt, 2012: 523) gibi kargışlarda görüldüğü üzere rızk anlamında sembolik olarak ekmek kavramından yararlanılmıştır.

Ekmek bolluk ve bereketle, uğur ve uğursuzlukla ilgili inançlarda da yer almış, kutsal kabul edilmiştir. Örneğin Malatya ili Arapgir ilçesinde "yağmur duası yapılmaya gidilmeden önce ilçe halkı kendi arasında bulgur, yağ, ekmek toplar. Dua yapılacak yerde yemek hazırlıkları yapılır. Şükür kurbanları kesilir ve genellikle pilav üstü et yemeği hazırlanılır. Yemek dua edilmeden önce hazırlanır ve duadan hemen sonra yemek orda hazır olanlara ikram edilir. Önemli bir uygulama da yemekten orda bulunmayan fakir halkın evine götürülüp ikram edilmesidir. Böylelikle yaratanın memnun edildiğine inanılır." (Köksal, 2018: 29). Yemek ve ekmek saçı görevi üstlenerek üstün gücün memnun edilmesinde aracı olarak kullanılmıştır. Geçiş dönemi âdetleri içerisinde var olan bir başka inanca göre "gebe kadının ekmek kırıntısına basması veya ekmek ya da hamur leğeninin üzerinden atlayarak geçmesi halinde doğacak çocuğun bir uzvu eksik olur" (Kurt, 2012: 29) ya da "gebe kadın rüyasında pişmiş ekmek görürse oğlu, ekmek hamuru görürse kızı olur." (Kurt, 2012: 38). 
Burada da görüldüğü gibi ekmek yaşanacak ya da yaşanabilecek olayların emaresidir. Ekmek en büyük nimetlerden biri olarak kabul edilmiştir, özellikle eski Türk inançlarının yansımalarını bulduğumuz uygulamalarda görüldüğü üzere ocaklıdan alınan bir parça ekmek şifa verir ve loğusa kadına koruyucu zırh olur. Yörede loğusa kadını al karısından korumak amacıyla "bir parça ekmek yastığının altına konur ya da ocaklı kişiden alınan bir parça ekmek önce loğusa kadına yedirilir ardından kalanı da yastık kılıfının içine konur. Ocaklının yaptı̆̆ı yemeyi yiyen loğusa kadına al basmaz." (Kurt, 2012: 66).

Kasaba halkı kültürel zenginliklerini geçmişten günümüze taşıyan bir topluluktur. Yiyecek ve içeceklerin törenlerde olmazsa olmaz şekilde özel olarak yapılanlarının yanı sıra bazıları geleneksel simgelere dönüşmekte ve özel anlam kazanmaktadır. Malatya ili Doğanşehir ilçesinde "kız istemeye gidilirken oğlan tarafı kül kömbesi yaparak götürür. Kız istendikten sonra kızın babası kömbeyi yerse kızını vermiş demektir." (Kurt, 2012: 113). Ekmeğin de bir besin maddesi, temel tüketim ürünü olmasının yanı sıra boyut atlayarak folklorik değer yüklendiği birçok gösterge vardır. Geleneksel törenler ve halk inançları içerisinde öneme haizdir. Yörede gerçekleştirilen düğün âdetleri içerisindeki yerini değerlendirdiğimizde bu durum somutlaşmaktadır. "Dügünden bir gün önce düğün yemeklerinde yenmek için yukalı denilen yufka ekmek yapılır. Bunun için sabah namazından sonra kadınlar toplanır ve teștlerde (bakır leğen) hamur yoğurur. Ekmek pişirme işi için görev dağılımı yapılmıştır; kimi hamur yoğurur, kimi ocağı yakar, ateş kayar, kimi hamuru açar, kimisi de ekmeği pişirirken bazı kadınlar da ekmeği muhafazaya alır. Yorulanın yerine başkası geçer. Arada kömbe de pişirilip yenir. Kadınlar türkü söyler, oynar. Akşamüstüne kadar ekmek pişirilir. Adına yukalı kaldırma denilen âdet yerine getirilir. Yufka ekmeği pişiren kadınlar, düğün sahiplerinden gelen kişilere aktaracın (ağaçtan yapılma uzunca kürek benzeri bir pişirme aracı) bir ucuna konmuş yufka ekmeği kaldırır, o kişi de 'Bereketli olsun.' sözleri ile birlikte sofra bezinin üstüne bahşiş atar. Yapılan ekmeğin bir kısmı dağıtılmaktadır." (Kurt, 2012: 127-128).

Doğum ve evlenme ile ilgili inançların yanı sıra askerlikle ilgili âdet ve inanmalarda da yeri olan ekmek, askere giden gencin bu dünyadaki rızkının devamlılığına bir işaret olarak yer bulmaktadır. "Askere gitmeden gence bir parça ekmek ya da kömbe ısırtılır, kalan kısmı da atılmaz, yüksekçe bir yere konur. Böylece gencin kısmetinin evden çıkmayacağı, dönüp gelerek lokmasını bitireceğine inanılır. Döndüğünde kalan lokma suya atılır ya da suda ıslatılıp kuşlara yem olarak bir yere birakılır." (Kurt, 2012: 223). Halk hekimliği uygulamalarında da yer bulan ekmek, yörede boğmaca hastalığının tedavisinde saçı olarak kullanılmaktadır. "Boğmacası olan çocuğu iyileştirmek dileğiyle yörede bulunan boğmaca kayasından geçirildikten sonra kayanın etrafına iki yağlı ekmek bırakılır." (Kurt, 2012: 372). 
Görüldüğü üzere farklı amaçlar ve değişik beklentilerle türlü şekillerde geleneksel inanç ve pratikler içerisinde yer alarak muhtelif uygulamalarla özel bir önemi olan ekmek, yörenin halk kültürü içerisinde işlevsel bir varlığa sahiptir. Mutfak kültürü zengin olan yörede, yufka ekmek (yukalı/sac ekmeği), bazlama, taş küllüğü, yăglı ekmek, yağlı ballı yufka, tandır ekmeği, taplama ekmeği, katmer, otlu ekmek, fasulye ekmeği, darı ekmeği, kete, dönderme, bilik ve kınalı ekmek gibi ekmek çeşitleri; pişirme șekilleri ve yapım usulleri ile ekmek çeșidi gıdalarla dahi yöre halk mutfağının çeşitliliğini sergilemektedir.

Yörede yaz kış hizmet veren bir ekmek fırını bulunmaktadır. Bu ekmek fırını, zaman kazandırarak iş yükünü azaltsa da yöre kadını kendi ekmeğini kendi yapma alışkanlığını kaybetmemiştir. Kültürel değişimlere rağmen geleneksel usullerle pişirilmesi sürdürülmekte olan ekmek çeşitleri sofralarda yer bulmaya devam etmektedir. Uzun yılların, yaşam tecrübelerinin birikimi bilgilerin nesiller boyu nakledilmesini sağlayan somut olmayan kültürel miras unsurları içerisinde yer alan mutfak kültürü, toplumun değişim ve gelişiminin belirgin olarak izlenmesine firsat veren kaynaklarından biridir. Kültürün değişimiyle beslenme alışkanlıkları değişmekte, beslenme alışkanlıklarının değişimiyle kültür değişmektedir. Çift yönlü bir ilişkinin söz konusu olduğu kültür-beslenme birbirine bağlı ve bağımlı bir özellik göstermektedir. Teknoloji ve küreselleşmenin derin etkileri ile değişime açık bir yapıya bürünen mutfak kültürü bu etkilere rağmen ulusal ve yerel dinamiklerini koruyan, uzun yılların alışkanlıklarını devam ettiren bağlı olarak nispeten durağan bir yapıyla çok fazla değişikliğe uğramamıştır.

Yöreye özgü bir ekmek çeşidi olan kınalı ekmek sıkça yapılan ekmek çeşitlerinden biri olmakla birlikte, yüzyıllardır yöre insanının vazgeçemediği bir besin türü olması bakımından değerlidir. Bir besin olarak kınalı ekmeğin folklorik değerine değinmeden önce ekmeğe ismini veren kınanın halk kültüründeki yerinden kısaca bahsetmek yararlı olacaktır. Maddi kültüre ait bir unsur olan kına, kadının süslenmede kullandığı bir malzeme olmasının yanı sıra halk inançlarında kötülükten korunmak, kutsal bir güç ve niyet için feda olmanın veya kurban etmenin göstergesi olarak hayrı ve bereketi sağlamak veya halk sağaltımında başta cilt hastalıkları olmak üzere çeşitli rahatsızlıkların tedavisinde yer alarak birçok pratikle geleneksel bir kullanıma sahiptir. Kına sözcügünün anlam evrenindeki mistik koruyuculuk ekmeğin kutsallığı ile birleşmekte, kınalı ekmekte bir renk ifadesi göstermesinin yanı sıra anlamsal bir zenginliğe ve derinliğe sahip olduğuna dikkati çekmektedir.

Anadolu'da bayram zamanı gerçekleştirilen adetler arasında var olan arife günü çocuklara, kurbanlıklara kına yakarak kutsamak; kınanın şans, bereket ve mutluluk simgesi olarak yer bulduğunu göstermektedir. Benzer şekilde önceleri yörede bayram zamanı özel olarak pişirilen ekmeğin de sıradan bir zamanda pişirilen ekmekten farklı olarak kınalı olması temelde 
özel bir anlamı barındırıyor olduğunu düşündürmektedir: Kınalı ekmek özel önem atfedilerek tören günlerinde, bayramlarda yapımı ihmal edilmeyen bir ekmek çeşididir. Ekmeğin baş tacı, sultanı olarak nitelendirilir (KK-1). Özellikle geçmiş dönemlerden günümüze bayram arifelerinde kınalı ekmek pişirmek bir âdettir. Önceleri süt hayvanı olanların süt hayvanı olmayanlara arife gününden önce büyük boy inek tası olarak tabir edilen kaplarla kınalı ekmek yapmak üzere süt dağıttıkları bilinmektedir. Geçmiş dönemlerde bayram ekmeği olarak Ramazan ve Kurban bayramlarında pişirilen kınalı günümüzde maddi imkânların genişlemesi ile birlikte daha sık yapılır durumdadır (KK-2).

Kırsal yaşam içerisinde sabah erkenden uyanan yöre kadını ekmek pişirme işi için günün erken saatlerini tercih eder. Henüz gün yeni doğarken yakılan ocaklarda sacın üstünde pişirilen ekmek, kadının günlük işlerini yapmadan, günün ilk öğününü hazırlamadan önce yaptığı ilk iştir. Bolluk ve bereket düşüncesiyle akşam güneşi battıktan sonra ekmek pişirilmez (KK1). Kınalı ekmek, ekmek yapımında en çok tercih edilen belli başlı maddelerden biri olan buğday unu ile yapılmaktadır. Geçmiş dönemlerde buğday ununun dahi kolay elde edilemediği yıllarda arpa unuyla pişirilmiştir (KK-2). Yöre halkı kınalı ekmek hamuru için kullanılan unu bizzat kendi tarlasına ektiği buğdaydan ya da yerel üreticilerden temin eder. Aşağı Oba ve Yukarı Oba olarak ikiye bölünen kasabada adı geçen bölgelerde birer değirmen bulunmakta, buğdaylar çoğunlukla burada öğütülmektedir.

Yörede her evin içinde veya bahçesinde bir sac ocağı kuruludur. Genellikle ekmek pişirme işinde ocağa pelit odunu/meşe odunu ya da kayısı odunu kullanılır. Kınalı ekmek, pişirme işlemi dişında iki aşamalı yapılmaktadır. Değirmende öğütülmüş tam buğday unu, su, tuz ve maya ile karıştırılarak yoğrulur ve üzeri hıla denilen bir çeşit bez örtü ile ya da tepsiyle kapatılarak akşamdan mayalanmaya bırakılır. Sabah kalkınca ekmek pişirmeye başlamadan önce açılan ekmek hamurunun üzerine sürmek üzere süt, yumurta, tereyağı, un, kaymak, çörek otu, boz çörek otu, susam, karbonat, dövülmüş ceviz ve tuz ile oluşturulan ve kınalı yüzü olarak ifade edilen çok katı ya da sıvı olmayacak bir şekilde orta kıvamda bir harç hazırlanır. Karbonat kınalının yüzünü kızartmak için eklenen bir malzemedir. Pişen ekmek yakılmış kına rengine ne kadar çok benzerse o kadar makbul olur. Harç karıştırılmaya başlanırken besmele çekilir ve "Benim elim değil Fatma Anamızın eli, Allah Halilullah bereketi versin" denir (KK-1, KK-2, KK-3).

Mayalı ekmek hamuru yufkadan kalın bir şekilde açllarak üzerine hazırlanan bu harçtan bolca sürülür. Harcın üzeri çatalla yol yol açılır. Bu şekilde pişince ekmeğin üstünde güzel bir desen olur (KK-1). Hamurun üzerine sürülen harcı dökmeden sacın üzerine almak da zahmetli bir iştir. Sac ocağının üzerinde hamur olan kısmı pişirilmeye bırakılır. Kaldırmaya elverişli bir duruma geldikten sonra yani yarı pişmiş haldeyken alınarak alt kısmı sac ocağının önüne, ateşin karşısında bulunan süğe denilen yassı taşın 
üstüne alınır. Süğe taşı önceleri dağlardan getirilen siyah taşların elle yontulması ile oluşturulurken günümüzde hazır malzemeden yapılmaktadır. Süğe taşının üzerine alınan kınalı ekmeğin böylece üstüne sürülen malzemenin de kızartılması sağlanır. Bu aşamada el çabukluğu gerekir, ardı ardına ekmek pişirmeye devam ederken ateşin karşısındaki kınalı sıkça çevrilerek adını aldığı kına rengini aldıktan sonra aktaraç (ağaçtan yapılma uzunca kürek benzeri bir pişirme aracı) yardımıyla taşın üstünden alınır. Hılanın üzerine konarak soğumaya bırakılır. Kınalı ekmek her ögünde yenebildiği gibi özellikle sabah sofralarında daha çok tüketilmektedir (KK-1, KK-2, KK-3).

Henüz çamaşırın elde yıkandığı dönemlerde her çamaşır yıkama işinden sonra mutlaka kül kömbesi ve kınalı ekmek pişirilirdi. Bayram zamanı erkekler sabah bayram namazına gider, namazdan döndüklerinde de kapısının önünde bekleyen ev sahipleri tarafından evlerine buyur edilir, yemeye davet edilirdi. Yöreye özgü bayram yiyeceği Polat köftesi olarak da bilinen içli köfteler sabah haşlanır ve gelen misafirlere ikram edilirdi. Bayram menüsünde Polat köftesi dışında kınalı ekmek ve kayısı hoşafı bulunurdu (KK-1, KK-2). Bu âdet günümüzde de devam etmektedir.

Kınalı ekmek yapıldığında konu komşuya da dağıtmak gözetilir. Kadınlar arasında kınalı ekmek yapma maharet göstergesi ve bir çeşit rekabet işidir. Temel malzemeleri ve pişirme tekniği aynı olmasına rağmen pişirilen kınalı ekmeğinin sırrını kimse kimseye vermez. Duygu ve hüner işi olarak görülür (KK-4). Kınalı ekmek son zamanlarda ekmek pişirme fırınlarında da yapılır olmuştur. Harç hazırlanıp fırına gönderilir ve firında hazırlanan ekmek hamurunun üzerine evlerde hazırlanmış kınalı harcı sürülür. Ancak bu işin kolayına kaçmaktır. Makbul olanı evde pişirilendir. Firınlarda yapılan kınalı ekmeğe sosyete kınalısı denmektedir (KK-1).

Halkın söyleyiş zenginliği ve dişavurum tarzının bir örneği olarak görünen sosyete kınalısı tanımlamasında da görüldüğü üzere sosyete kelimesi önüne eklendiği kavrama olumsuz çağrıșımlar yükleyebilmektedir. Gelir düzeyi yüksek ve buna bağlı olarak farklı yaşam etkinliklerine sahip olan seçkin bir tabakanın ifade edildiği sosyete kelimesi halk dilinde küçümseyici bir tavrın göstergesi olarak karşımıza çıkmaktadır. Bu şekilde bir ifade biçimi, benzer biçimde sosyete mantısı örneğinde olduğu gibi yapılan yiyeceğin gelenekselden ayrıldığının, modern bir yoruma tabi tutulduğunun ve dolayısıyla bünyesindeki özgün niteliği ve sahip olduğu değeri yitirdiğinin anlatımıdır.

\section{Sonuç}

Malatya yöresinin zengin halk kültürü içerisinde Polat kasabasının özel bir yeri vardır. Gelenek ve göreneklerine bağlılıkları ile kültürel değerlerini yaşatmaya devam eden yörenin tarihine bakıldığında Türk varlığının 1200'lü yıllara dayandığı görülmektedir. Selçuklular döneminden Cumhuriyet'e yörede yaşanan sosyal, siyasi, kültürel birtakım gelişme ve değişmeyle birlikte, halk yaratması birçok üründe milli kültürün, göçebe 
yaşam kalıntılarının izlerini görmek mümkündür. Geçmiş yaşam izlerimizi takip edebildiğimiz halk ürünleri arasında yöresel yiyecekler de bulunmaktadır. Kültürün en canlı ve en etkin unsurlarından biri olan mutfak kültürü insanın temel ihtiyacı olan beslenme işleminin haricinde milletlere özgü geleneksel içerik ve uygulanma biçimleri ile milli kimliği yansıtan bir derinliğe sahiptir. Bir toplumun mutfak kültürünün seyri değerlendirildiğinde o toplumun ekonomik, sosyal ve kültürel bağlamda yaşanmışlıkları da ortaya çıkarılabilir. Kültürel miras Türk insanının binlerce yıllık yaşam çizgisi üzerinden üretkenliği ile var ettiği ve günümüze kadar aktardığı yiyecek-içecekler ile bunları oluşturma teknikleri, saklama ve koruma yöntemleri ile milli öze ait davranış formlarını içermektedir. Millet olma özelliğine kavuşturan kültürel değerler içerisinde toplumların geçmişten günümüze taşıdığı inançlarını, koşullu davranışlarını ve zevklerini yansıtan mutfak kültürü özel bir yere sahiptir.

Türk mutfak kültürü yaşaması ve sonraki nesillere ulaştırılması gereken kültürel unsurlardan biri olarak oldukça variyetli ve köklü bir yapıya sahiptir. Polat Kasabası halk mutfağı da bu zenginliğin bir parçasıdır. Türk mutfak kültürü yaşatılması ve sahip olduğu olgunluk ile sürekliliği sağlanması gereken kültürel unsurlardan biri olmanın ötesinde dünya lezzet ekonomisi içerisinde hak ettiği paya kavuşturulması gereken zenginliklerimizin başında gelmektedir. Milli kültürün bir bölümünü oluşturan mutfak kültürünün içerisinde yer alan yöresel yiyecekler, üreticisi havaliye özgü bir üretim ve tüketim faaliyeti olarak içeriği, hazırlanışı, pişirme tekniği, tüketim zamanı, tüketim şekli yüklendiği inanca bağlı geleneksel anlamlar ile ulusal kimliğe ilintili olarak korunması, yaşatılması ve aktarılması esastır.

Büyük oranda teknolojik etkilere kapalı geleneksel esaslarla yapımı devam eden kınalı ekmek, yöresel yiyecekler kategorisinde sadece Polat yöresi halkınca biliniyor ve yapılıyor olması ile özel bir ekmek çeşididir. Bugün yapımının daha kolay olarak pişirme firınlarında yapılmaya başlanması halk dilinde zahmetsiz anlamında sosyete kınalısı adını almasına sebep olmuştur. Bu ifade biçimi temelde bir eleştiri göstergesi olmasının yanı sıra geleneksel olandan kopuşu da izah etmektedir. Bu bağlamda Polat yöresi kültürel mirasının içerisinde kendine özgü geleneksel halk mutfă̆ı hazinesinin korunarak özgün tatlarının muhafaza edilmesi gerekmektedir. $\mathrm{Bu}$ özgün tatlar arasında hâlihazırda yapımı sürdürülen kınalı ekmek yerelden ulusala, ulusaldan evrensele taşınarak farkında olunmayan bu lezzetin ülke ve dünya tat ekonomisinde yerini alması, buna bağlı olarak da turizm değeri yüklenmesi adına tanıtım çalışmalarının yapılması sağlanmalıdır. 


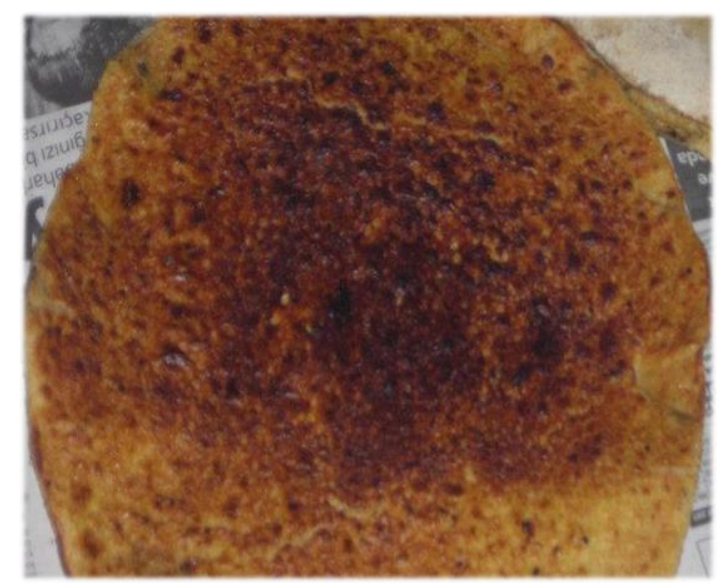

Kınalı ekmek

\section{KAYNAKÇA}

\section{Yazılı Kaynaklar}

Artun, E. (2012). Türk halkbilimi. Adana: Karahan Kitabevi.

Başkan, K. - Avcıkurt, C. (2015). Kültürel miras değeri olarak somut olmayan geleneksel tören keşkeği incelenmesi. Doğu Karadeniz Bölgesi Sürdürülebilir Turizm Kongresi Bildirileri, 618-626, Gümüşhane: Gümüşhane Üniversitesi.

Bayoğlu, A,(2014). Erzurum'da lavaş (Acem Ekmeği), Atatürk Üniversitesi Edebiyat Fakültesi Sosyal Bilimler Dergisi, 53, 163-186.

Baysal, A. - Över, N. (1994). Ekmek: Beslenme ve sağlık yönünden önemi. Türk Mutfak Kültürü Üzerine Araştırmalar, Geleneksel Ekmekçilik Hamurişi Yemekler, 40-49, Ankara: Türk Halk Kültürünü Araştırma ve Tanıtma Vakfı.

Bessière, J. (1998). Local development and heritage: Traditional food and cuisine as tourists attractions in rural areas. Sociologia Ruralis, 38(1), 21-34.

Beşirli, H. (2010). Yemek, kültür ve kimlik. Milli Folklor, 87, 159-169.

Birer, S. (1990). Türk mutfağının tarihsel gelişim süreci içerisindeki değişimi ve bugünkü durumu. Beslenme ve Diyet Dergisi, 19, 251-260.

Çapar, G. - Yenipınar, U. (2016). Somut olmayan kültürel miras kaynağı olarak yöresel yiyeceklerin turizm endüstrisinde kullanılması. Journal of Tourism and Gastronomy Studies, 4, 100-115.

Delind, L. B. (2006). Of bodies, place and culture: Re: Situating local food. Journal of Agricultural and Environmental Ethics, 19, 121-146.

Demirgül, F. (2018). Çadırdan saraya Türk mutfağı. Uluslararası Türk Dünyası Turizm Araştırmaları Dergisi, 3 (1), 105-125.

Goode, J. (2005). Yemek. Milli Folklor, 67, 172-176.

Göde, H. A. - Tatlıcan, N. (2016). Geleneksel Isparta ekmeği etrafında şekillenen somut olmayan kültürel mirasın turistik, eğitimsel ve ekonomik ișlevlerinin yaratılmasına yönelik yaklaşımlar. SDÜ Fen Edebiyat Fakültesi Sosyal Bilimler Dergisi, 38, 125-143.

Kabak, T. (2017). Beslenme ve mutfak ekseninde somut kültürel unsurlar. Halk Bilimi El Kitabı, (Ed. Mustafa Aça), 281-291, İstanbul: Motif Vakfı. 
Köksal, H. (2018). Malatya ili Arapgir ilçesi halk inanışları. Elazı̆̆: Fırat Üniversitesi Sosyal Bilimler Enstitüsü Yayımlanmamış Yüksek Lisans Tezi.

Kurt, B. (2012). Malatya ili Doğanşehir ilçesi halk kültürü araştırması. Adana: Çukurova Üniversitesi Sosyal Bilimler Enstitüsü Yayımlanmamış Yüksek Lisans Tezi.

Oğuz, Ö. (2009). Somut olmayan kültürel miras ve kültürel ifade çeşitliliği. Milli Folklor, 89, 6-12.

Oğuz, Ö. (2013). Terim olarak somut olmayan kültürel miras. Milli Folklor, 100, 513.

Ögel, B. (1982). Türk mutfağının gelişmesi ve Türk tarih gelenekleri. Türk Mutfă̆ı Sempozyumu Bildirileri, 15-18, Ankara: Kültür ve Turizm Bakanlığı, MİFAD.

Saruhan, G. E. (2012). Kentsel markalaşma sürecine kültür turizminin etkisi: Antakya (Hatay) örneği. Ankara: Atılım Üniversitesi Sosyal Bilimler Enstitüsü Yayınlanmamış Yüksek Lisans Tezi.

Sürücüoğlu, M. S. - Özçelik, A. Ö. (2008). Türk mutfak ve beslenme kültürünün tarihsel gelişimi. 38. ICANAS Kongresi Bildirileri, Maddi Kültür III. Cilt, 12891310, Ankara: Atatürk Kültür, Dil ve Tarih Yüksek Kurumu.

Tezcan, M. (2000). Türk yemek antropolojisi yazıları. Ankara: Kültür Bakanlığı.

\section{Sözlü Kaynaklar}

KK-1: Zübeyde Demiralp, 1954, Malatya/Polat, ilkokul mezunu, ev kadını. (Görüşme: 13.01.2020)

KK-2: Neriman Demiralp, 1960, Malatya/Polat, ortaokul mezunu, ev kadını. (Görüşme: 16.01.2020)

KK-3: Seher Küçük, 1958, Malatya/Polat, ilkokul mezunu, ev kadını. (Görüşme: 25.12.2019)

KK-4: Münevver Kurt, 1967, Malatya/Polat, lise mezunu, ev kadını. (Görüşme: 25.12.2019) 